\title{
NUEVOS DATOS SOBRE LOS ALTARES TAURODÉRMICOS ASIRIOS Y ESCITAS Y SU SIMBOLOGÍA
}

\author{
NEW DATA ON ASSYRIAN AND SCYTHIAN BULL-SKIN-SHAPED SHRINES AND THEIR SYMBOLISM
}

ÁLVARO GÓMEZ PEÑA ${ }^{1}$

Universidad de Sevilla

La investigación centrada en el ámbito protohistórico de la Península Ibérica ha venido en los últimos años incrementando en los estudios el protagonismo de los elementos taurodérmicos aparecidos en España y Portugal, fruto de lo cual se ha puesto mayor énfasis en detectar este tipo de formas en los trabajos de campo, con la consecuente mayor importancia en los respectivos estudios posteriores. Esta retroalimentación de la publicación al campo y del campo a la publicación ha acabado pasando con el número creciente de ejemplares de la mera atestiguación como objetos en contextos cultuales a ser actualmente centro de interpretaciones identitarias dado el carácter simbólico, comercial y elitista que se les ha otorgado. Así, dos tendencias están actualmente en contraposición. De una parte, la de aquellos que ven los taurodermos en general, y los altares de esta forma en particular, como propios de la población residente que habitaba en el suroeste a la venida de gentes orientales, habiéndose asumido dicho perfil como símbolo identitario de la élite fruto de su introducción en los circuitos mediterráneos del comercio del metal (Celestino, 1994, 306-309; Murillo et alii, 2005, 16-17; Gómez Toscano, 2009; Fernández y Buero, 2010). Quienes así opinan, basan su argumento en la existencia de lingotes de cobre de la misma forma fechados en la segunda mitad del II milenio a. C., por lo que son estos lingotes los que servirían de inspiración a los altares, negando que en oriente existan ya tales aras con idéntica forma. De otra parte, la segunda de las interpretaciones aquí defendidas ve en estos altares la continuidad en suelo ibérico de tradiciones litúrgicas orientales traídas a occidente

\footnotetext{
1. Becario PIF adscrito al área de Prehistoria de la Universidad de Sevilla. Miembro del Grupo de Investigación Historiografía y Patrimonio Andaluz (HUM-402). Consejería de Cultura de la Junta de Andalucía.
}

por poblaciones de aquel lado del Mediterráneo, idea basada en la comparación de smiting-gods y representaciones en cilindros-sellos chipriotas y ugaríticos con los contextos hispanos (Escacena, 2007; Escacena y Coto, 2010; Gómez Peña, 2010).

Como muchos asuntos de especial relevancia en la religiosidad tartésica, el de los taurodermos empezó a tener su razón de ser a partir de las excavaciones de El Carambolo y más concretamente con la aparición de su famoso tesoro. Así, al abordar el estudio del mismo a finales de los años cincuenta, E. Kukahn y A. Blanco empezaron a relacionar ambos extremos del Mediterráneo a propósito de los paralelos con que podían contar los conocidos por aquel entonces como «pectorales» del conjunto áureo:

\begin{abstract}
"Como motivo ornamental se encuentra en vasos micénicos, en los tableros de marfil, para juego, de Megiddo, en las pinturas de los palacios asirios y sirios de Khorsabad, Arslan-Tash, Tel-Barsib, etc., e incluso en lingotes de cobre de la época premonetal que aspiran a reproducir la piel extendida de un buey" (Kukahn y Blanco, 1959, 42).
\end{abstract}

Vemos cómo desde bien pronto se realizó una llamada de atención tanto sobre los lingotes de cobre como sobre dichas pinturas en las paredes de algunos palacios asirios y sirios, idea esta última que sólo ha sido rescatada del olvido casi cincuenta años después por autores como J. Maier $(2003,100)$ y J. L. Escacena (2006, 137-138; 2011, 173; Escacena y Coto, 2010, 163 y ss.). Vaya por delante que no pretendemos en estas líneas defender que los altares taurodérmicos peninsulares sean una continuidad directa de las representaciones asirias, sino poner de manifiesto que dichas aras son el reflejo de una idea extendida por el Mediterráneo Oriental, especialmente en Chipre y Siria, que tiene su reflejo arqueológico en la Asiria de los siglos IX-VI a. C., así como en la cultura escita desde el siglo IV a. C. en adelante. 


\section{LA HIPÓTESIS PANLINGOTISTA}

¿Son los altares una creación ex novo propia de la cultura tartésica o por el contrario ya existían sus precedentes en el Mediterráneo Oriental? Como se puede observar, el panorama de la investigación vuelve a vérselas con el sempiterno dilema entre autoctonismo y aloctonismo, problema que afecta gravemente a casi todos los sectores de la arqueología tartésica. Y si se me permite acuñar la expresión, la hipótesis autoctonista podría reducirse a una visión panlingotista, es decir, a tomar por lingote taurodérmico todo lo que en Oriente ha mostrado este perfil. Repasando la historiografía sobre este particular, se puede observar claramente cómo la sucesión de hallazgos y de interpretaciones ha marcado en gran medida a esta vía.

El primer hito en esta sucesión de descubrimientos, a pesar de los paralelos apuntados por E. Kukahn y A. Blanco, es el del hallazgo de una, por entonces, fuente de bronce forjado que apareció en la tumba 16 de la necrópolis de La Joya (Huelva), la cual llevó a sus descubridores a poner como paralelo para su contorno al "lingote de cobre chipriota o talento" (Garrido y Orta, 1978, 49). Así, veinte años después del descubrimiento de los «pectorales», ambos autores se decantaban por una opción y silenciaban otra, quizás dejados llevar por la similitud del material del que estaba hecho el reinterpretado posteriormente como altar portátil (Escacena e Izquierdo, 2000, 24) con el metal del que estaban facturados los lingotes, los cuales tenían la filiación chipriota con la que los publicadores de las excavaciones de La Joya vincularon muchos de los objetos aparecidos en el interior de las tumbas exhumadas (Garrido y Orta, 1978).

A este hallazgo y a su respectiva asimilación le sucedió otro igualmente importante, el del monumento turriforme de Pozo Moro, cuya base tenía para su excavador el mismo paralelo (Almagro-Gorbea, $1983)^{2}$. Fue este hallazgo el que influyó a sucesivos investigadores a presentar en las actas del I Congreso de Arqueología Ibérica varias tumbas procedentes de diversas necrópolis del sureste español íntimamente relacionadas con la forma a estudio. La tumba $31 \mathrm{de}$ la necrópolis de los Villares (Hoya Gonzalo, Albacete) presentaba este contorno por partida triple: el lugar en el que se encontraron los restos óseos, la propia forma de la tumba y el cerramiento de ésta (Blánquez, 1992, 255), poniéndolo en relación con el pavimento del monumento turriforme de Pozo Moro, lo que nos demuestra la influencia de esta tumba para este tipo de interpretaciones; unas páginas después, J. M. García Cano daba a conocer otra tumba hallada en la

2. Recientemente, M. Almagro-Gorbea contempla ya no sólo como posible ejemplo a imitar los lingotes y los keftiu, sino también las pieles de toro para el caso de la base de la tumba 20 de Galera (Almagro-Gorbea, 2009, 10), más conocida por haberse hallado en su interior la "dama de Galera". necrópolis de Castillejo de los Baños (Fortuna, Murcia) con forma, también para su excavador, de lingote chipriota (García Cano, 1992, 321); la última de las referencias a una sepultura con idéntica forma realizada en dicho congreso se trata de la famosa tumba $\mathrm{n}^{\circ} 155$ de la necrópolis ibérica de Baza (Ruiz et alii, 1992, 411), la cual ya hemos expresado en una publicación previa que no debe ser relacionada ni con la forma de lingote chipriota ni con la de piel de bóvido (Gómez Peña, e. p.).

Mucho tienen que ver en esta interpretación por tanto tres factores: en primer lugar, el impacto de los hallazgos de La Joya y Pozo Moro y su posterior explicación que silenciaron la hipótesis taurodérmica; en segundo lugar, el desconocimiento por parte de los investigadores tanto del trabajo peletero como del resultado que tenían las pieles bovinas tras ser desolladas y perfiladas; $y$ en tercer lugar, el eco internacional de los hallazgos durante el siglo XX de dos pecios hundidos frente a las costas de la actual Turquía en los que se encontró entre su cargamento cientos de lingotes con esta forma (Gómez Peña, 2010), opinión que suscribió entre otros J. Maluquer de Motes, quien relacionó los "pectorales" de El Carambolo con estas piezas metalúrgicas y por extensión con las ricas minas tartésicas, no dando cuenta de la posibilidad de estar ante pieles de animales:

"Los grandes pectorales, en realidad, no sabemos cómo se llevarían. Su forma es ciertamente la de los lingotes o galápagos de metal" (Maluquer de Motes, 1984 [1970], 135).

Pero especialmente importante fue la interpretación que se había realizado de dos smiting-gods, uno masculino y otro femenino, que aparecen sobre dos peanas con forma de lingote a ojos de sus intérpretes (Schaeffer, 1971; Catling, 1971) dado que por aquel entonces todavía no se habían descubierto altares taurodérmicos como los aparecidos en la Península Ibérica. A pesar de todo, ya en el Mediterráneo Oriental se conocía la relación entre lingotes y pieles, sin embargo se descartó tal arguyendo que el parecido formal era puramente casual ya que el contorno de los primeros se había realizado para facilitar su transporte sobre los hombros de sus portadores (Bass, 1961, 272; 1986, 275; Pulak, 1988,6 , nota a pie 8). No obstante, no podemos saber con seguridad si la forma se escogió por su fácil transporte o si aquélla acabó encontrando buen acomodo en los hombros de sus cargadores, pero lo que tenemos claro es que su más fácil transporte y su simbología no son incompatibles, toda vez que de la propia Chipre tenemos testimonios que nos dejan ver a las claras que pieles y lingotes tuvieron la misma forma (Fig. 1).

Así pues, vistas en perspectiva todas estas interpretaciones, el paradigma panlingotista en ningún caso ha dado datos en contra de que los lingotes no puedan ser interpretados como pieles de bóvido. Más bien sus partidarios han rehusado utilizar esta hipótesis en una 


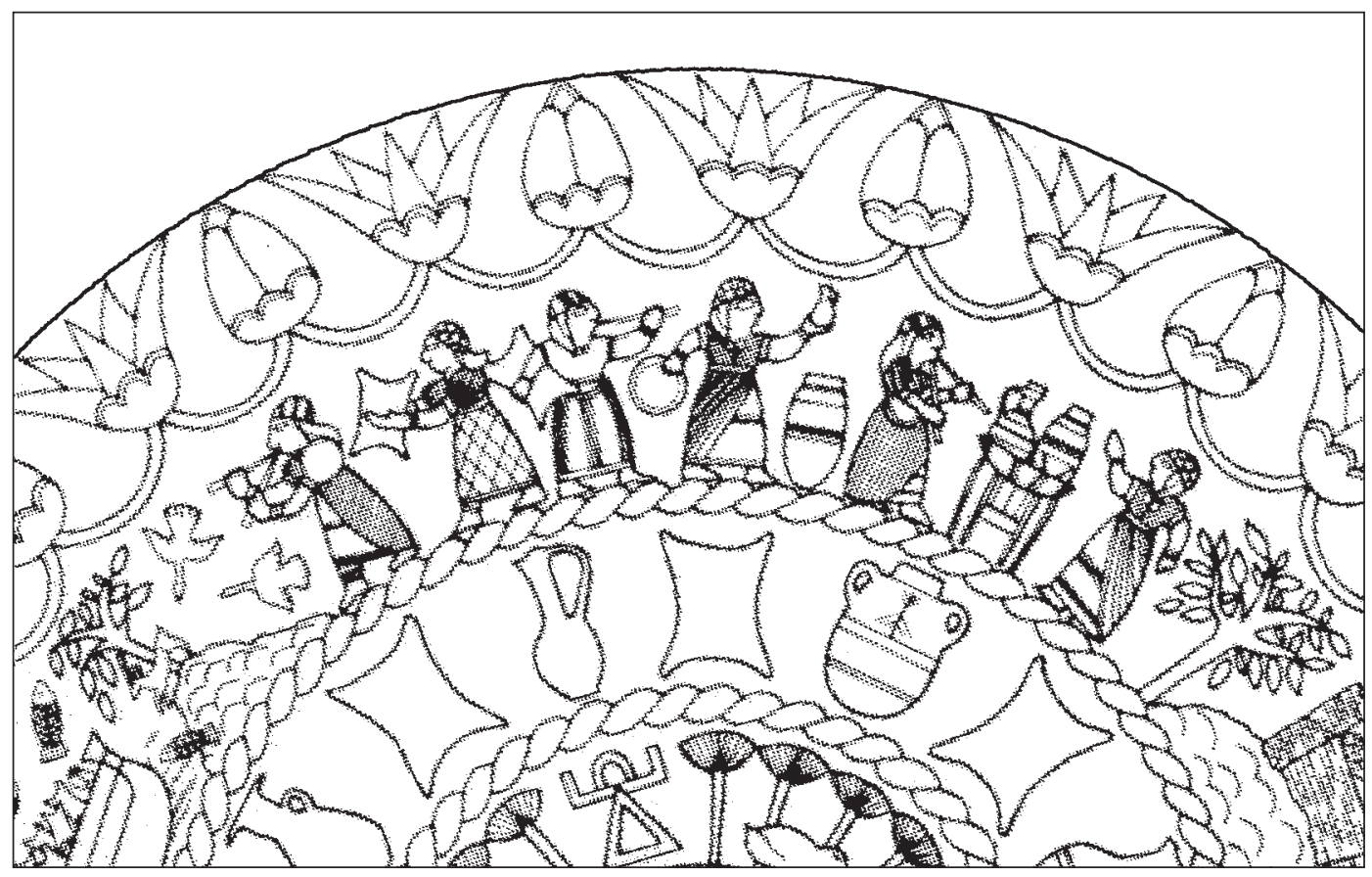

Figura 1: Fuente de bronce con la representación de lingotes taurodérmicos siendo transportados en barco así como tambores en forma de piel de bóvido de idéntico perfil en las manos del cuerpo de música y baile femenino (Bikai, 1987, portada).

muestra de ceguera metodológica cuando han estudiado los pecios orientales del II milenio a. C., lo que habla nada bien de la praxis científica de sus autores, con el consiguiente espejismo entre los investigadores que se han servido de tal presupuesto para afirmar que tales altares no existen en el Mediterráneo Oriental, y que lo único que reflejan es la introducción de la población residente tartésica en las esferas económicas mediterráneas al hacer suyo un símbolo económico como eran los lingotes, tengan estos forma de piel de bóvido o no (Gómez Toscano, 2009, 42 y ss.). A este respecto cabría plantearse la siguiente cuestión: si los altares son una creación controlada por la población autóctona dado que no existen ejemplares en oriente, ¿por qué pensar que la élite tartésica usó los lingotes como símbolo para sus aras si no han aparecido tales lingotes en toda su área de influencia? El argumento usado en contra de la hipótesis taurodérmica es, por tanto, fácilmente utilizable contra la panlingotista (i!).

\section{LA HIPÓTESIS TAURODÉRMICA}

Por otra parte, como venimos diciendo, se encuentra la hipótesis que ve en los altares el reflejo directo de la piel de un bóvido, cuyo primer claro defensor fue J. L. Escacena, quien como director de las excavaciones del yacimiento de Caura (Coria del Río, Sevilla) interpretó las dos aras allí aparecidas como el trasunto de una piel de toro tanto por sus características formales, como por las cromáticas y las simbólicas. Pero no sólo estos datos refuerzan esta idea, sino la propia presencia de un receptáculo en uno de sus extremos que representa el cuello del animal (Escacena e Izquierdo, 2000, 23; Escacena, 2006, 131-133). Hipótesis a la que se han sumado con el paso de los años varios investigadores que han tratado sobre este particular desde diferentes ópticas (Maier, 2003; Marín, 2006; López Pardo, 2006; Celestino, 2008; Almagro-Gorbea, 2009). Sin embargo, todavía hay quienes siguen pensando que los altares taurodérmicos no son otra cosa que la representación de "lingotes chipriotas", unas veces por desconocimiento del trabajo de las pieles y de su simbología (Fernández y Buero, 2010), otras por querer vincular a las poblaciones autóctonas con el control metalífero frente a las alóctonas (Gómez Toscano, 2009).

Sin embargo, esta interpretación taurodérmica se ve dividida entre quienes piensan que a pesar de ser pieles de bóvido, la originalidad de los altares es autóctona y no propiamente oriental. Desde esta segunda óptica somos varios los autores que hemos defendido que los taurodermos de la Península Ibérica no son los únicos testimonios arqueológicos con los que contar para poder relacionar ambas formas a uno y otro lado del Mediterráneo, para lo que venimos proponiendo una aproximación metodológica que nos permita inferir con la mayor claridad posible si los elementos a estudio son altares con forma de piel de bóvido o no. Así, hasta la fecha son en torno a cincuenta los elementos protohistóricos aparecidos en la Península Ibérica que pueden ser relacionados con una piel de toro trabajada, la mayoría de ellos asociados a santuarios y a tumbas (Gómez Peña, e. p.). A casi todos ellos se les ha identificado como tales taurodermos usando como únicos criterios la forma y su doble contorno cuando éste lo presenta, resultado del contraste visual entre la zona 


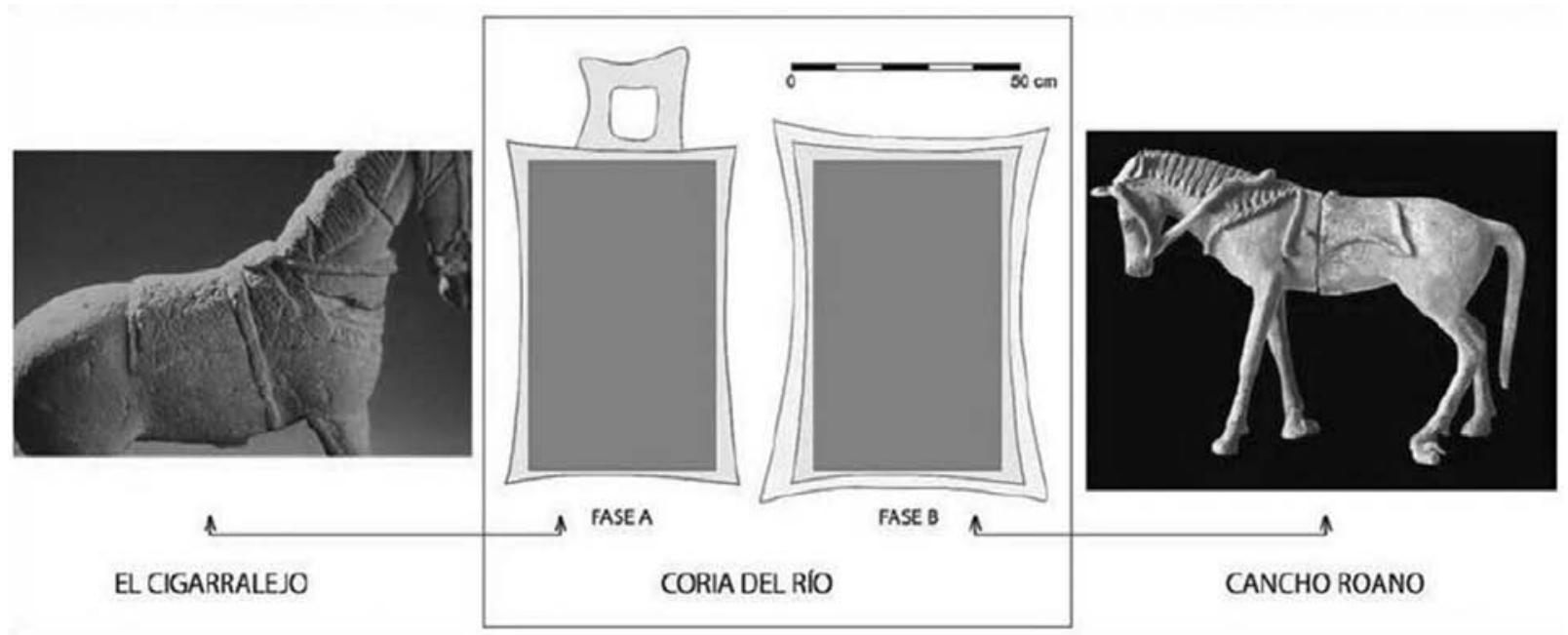

Figura 2: En el centro los altares de Caura de las fases A y B. A la izquierda, caballo de El Cigarralejo (Mula, Murcia) presentando en la montura la lengüeta correspondiente al cuello plegado hacia atrás, como el altar de la fase A. A la derecha, yegua de Cancho Roano (Zalamea de la Serena, Badajoz) con montura de piel igual a la de la fase B de Caura (Escacena y Coto, 2010, 159).

exterior rasurada y la zona interior que conservaba el pelo (Fig. 2). Sin embargo, a nuestro juicio, la similitud formal no debe de ser el único criterio a seguir para saber si estamos ante un objeto de forma taurodérmica en tanto que puede haberse llegado a él por convergencia y no por homología ${ }^{3}$. Por tanto, para una mejor comprensión del asunto a tratar en estas líneas, apuntamos la metodología utilizada por nosotros, con la que pretendemos matizar la anterior propuesta de J. L. Escacena y R. Izquierdo (2000) para fijar las características que permitan identificar tanto a los elementos taurodérmicos en general como a los que cumplieron la función real o simbólica de altares.

En primer lugar, queremos llamar la atención sobre una cuestión que a pesar de ser obvia no deja a veces de ser ignorada (Fernández y Buero, 2010, 94). A saber, que los objetos taurodérmicos imitan el resultado de las pieles trabajadas, por lo que si tenemos que considerar cuál es el primer criterio para definir qué tiene forma taurodérmica y qué no, debemos de establecer paralelos formales con representaciones trabajadas en piel o en cuero. Este primer paso nos abrirá una gama de resultados posibles según el número de formas finales que encontremos y que nos servirá para poder empezar a hipotetizar sobre si el objeto de estudio en cuestión es taurodérmico o no. Pero no debemos de quedarnos sólo en la forma del contorno, como acabamos de indicar. Pueden existir otras características

3. Entiéndase por homología la definición utilizada en biología que hace referencia a la relación de correspondencia que ofrecen entre sí partes que en diversos organismos tienen el mismo origen aunque su función pueda ser diferente. En oposición a esta definición se encuentra la de convergencia, que indica la similitud que ofrecen entre sí partes de diversos organismos sin tener un origen común, independientemente de cuál sea nuevamente su función. que se aprecien en las representaciones de los propios objetos en piel o en cuero que podrían reforzar la hipótesis que ve en estos elementos dicha forma. El requisito sine qua non para identificar a los ejemplares taurodérmicos en general y protohistóricos en particular es sencillo, pero lo realmente necesario para saber si tal objeto es un altar o no reside en la búsqueda de representaciones o referencias literarias que recojan prácticas cultuales en las que aparezcan y que nos ayuden a inferir características específicas sobre la forma y rituales realizados en ellos.

Como acabamos de mencionar, ya J. L. Escacena y R. Izquierdo elaboraron una metodología para intentar definir qué elementos taurodérmicos pueden ser considerados altares y cuáles no para el ámbito de la protohistoria peninsular ibérica (Escacena e Izquierdo, 2000, 27-28). En su estudio, ambos autores proponen tomar cuatro características como fundamentales. En primer lugar, la propia forma del objeto, que suele presentar en cada extremo del cuerpo un alargamiento intencionado que representa el comienzo de las extremidades del animal, a lo que venimos a sumar la posibilidad de un doble contorno; la segunda característica, la presencia de un focus central debido al fuego causante de la combustión de la víctima dada como ofrenda sobre su superficie, lo cual delata su función como altar; en tercer lugar, el carácter exento de la construcción dada la posible necesidad de realizar ritos de circunvalación; y, por último para el caso de los altares inmuebles, la orientación astronómica de la pieza hacia los solsticios de verano y de invierno, reflejo de la creencia en una divinidad que resucita dado el progresivo descenso y aumento de horas de sol tras ambos días respectivamente.

Evidentemente, cuantas más coincidencias con estos cuatro puntos presenten los elementos a estudio, mejor explicará esta metodología su simbología. Sin 
embargo se nos antoja necesario recalcar un hecho. ¿Qué hacer cuando el objeto está representado pictóricamente o escultóricamente, y no arquitectónicamente? Para este particular, el tercer y cuarto puntos, los concernientes a la circunvalación y orientación astronómica de los mismos, no son válidos dado que no es verificable en todos los casos. Sin embargo, se debe de plantear una nueva característica: la representación de elementos que nos indiquen que asistimos a un ritual sobre el altar o en torno a él, o a momentos previos de éste, lo que vendría a ser un fuerte paralelo arqueológico con la búsqueda de tales indicios entre las fuentes textuales, como comentábamos anteriormente.

\section{EL ORIGEN ORIENTAL DE LOS ALTARES TAURO- DÉRMICOS PENINSULARES}

Es, por tanto, esta metodología la que hemos utilizado para poder reinterpretar desde la tradición cananea una serie de formas aparecidas en cilindros-sellos hallados en Ras Shamra (Ugarit) y que han sido tradicionalmente interpretadas como lingotes dados los paralelos con que se contaba hasta la aparición de los altares en la Península Ibérica. Se trata de dos sellos en los que aparecen sendas formas de piel de bóvido en un contexto claramente ritual.

En el primero de ellos, procedente del Museo de Aleppo (RS 6127), se observa a un hombre de pie afrontado a un animal estilizado al que se aproxima en actitud de asirle por los cuernos, los cuales son de perfil curvado hacia atrás, lo que nos hace asimilar a este animal con una cabra. Tras ella, otro animal de menor estatura le sigue en la misma dirección. Ambos podrían estar siendo dirigidos hacia la pieza que se encuentra detrás de la figura humana ${ }^{4}$, de clara silueta taurodérmica y que aparece representada desde una visión cenital para que se vea su forma. Esta pieza podría tratarse de un altar hacia el que ambas víctimas se estarían encaminando para ser sacrificadas (Fig. 3). Entre la posible ara y el último de los animales, un pájaro de significado incierto, y entre ambos animales un símbolo astral representado por un conjunto de puntos identificable quizás con el cúmulo de las Pléyades, cierran el conjunto de figuras (Bordreuil y Gubel, 1990, 484, fig. 2; Lagarce y Lagarce, 1997, 80, fig. 4, abajo).

En la segunda de las piezas (Lagarce y Lagarce, 1997, 80, fig. 4, arriba) se observa la figura de un hombre sentado sobre una silla baja que porta unos cuernos en su cabeza similares también, como en el primer se1lo, a los de una cabra, en ademán de coger a un animal de su cornamenta y alzando amenazante la otra mano quizás en actitud de sacrificio. Resulta sugerente a este respecto observar la posición en la que se encuentra

4. Los cilindros-sellos tienen la peculiaridad de no señalar cuál es el comienzo y el final de la escena.

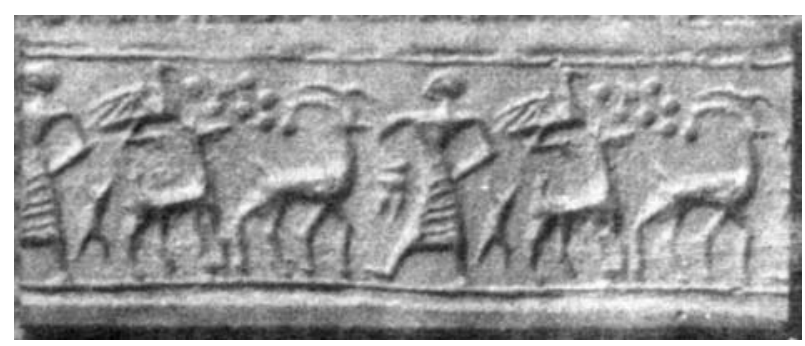

Figura 3: Cilindro-sello ugarítico actualmente en el Museo de Aleppo (Lagarce y Lagarce 1997: 80).

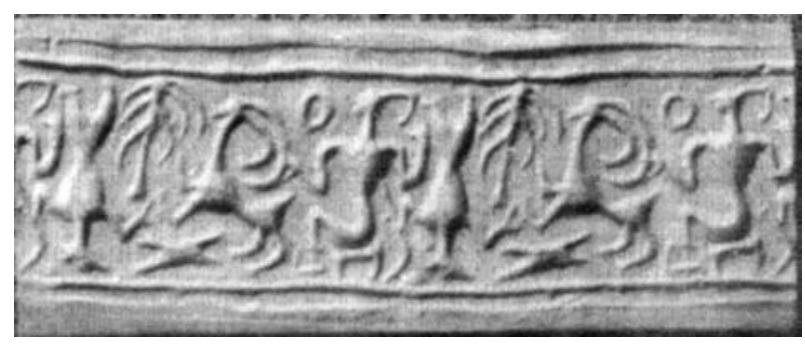

Figura 4: Cilindro-sello procedente de Ugarit (Lagarce y Lagarce 1997: 80).

el animal, de nuevo una cabra según la forma de sus cuernos, pues la mitad delantera de su cuerpo se encuentra sobre otro elemento de forma taurodérmica, esta vez representado desde su cenit en horizontal para que su forma pueda ser vista de acuerdo con la orientación del cuerpo del animal (Fig. 4). Nuevamente interpretamos esta pieza como un altar taurodérmico, acompañado esta vez de un árbol identificable con una asherah, árbol sagrado de tradición cananea y fenicia que recoge las propiedades de las divinidades femeninas semitas (van der Toorn et alii, 1999, 101). Un elemento más representado en el sello es una figura redondeada a la que se le representa su contorno y que relacionamos con un símbolo astral quizás identificable con el Sol o con la Luna. Todos estos elementos nos vuelven a hacer pensar que estamos ante la plasmación de un ritual sacrificial. Por último, una figura humana bocabajo sosteniendo un objeto alargado con su mano cierra la escena sin que podamos hipotetizar sobre ella.

Al igual que estos dos cilindros-sellos hallados en Ugarit, de Chipre procede una buena muestra de cilindros-sellos en los que se aprecia la misma forma taurodérmica (Fig. 5), de los que la mayor parte son de Enkomi. Las escenas representan la misma temática que las procedentes de Ugarit pero no muestran escenas con animales, sino otras más simbólicas en todos los casos que conocemos. En ellas se suelen repetir una serie de elementos ya vistos en los anteriores cilindros-sellos: un personaje masculino de pie, un supuesto lingote de forma taurodérmica, un árbol, una cabra y en ocasiones bucráneos o cornamentas. Los paralelos visibles con los ejemplares ugaríticos nos remiten al mismo ámbito religioso del que hemos hecho mención antes. Los hasta ahora considerados 
A

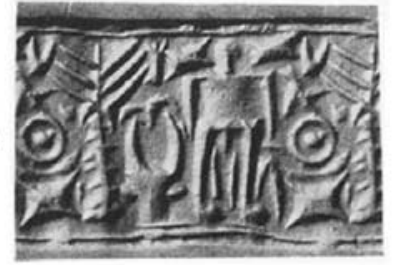

B

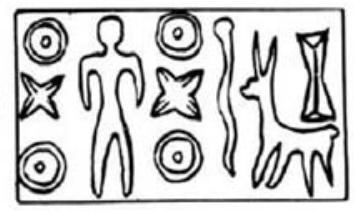

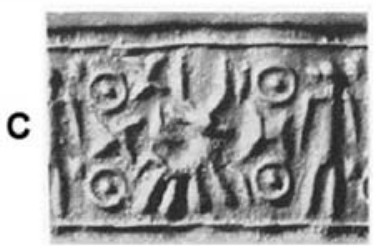

D

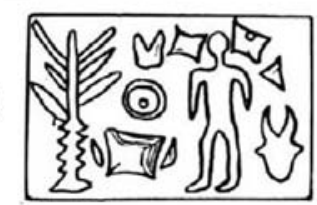

E

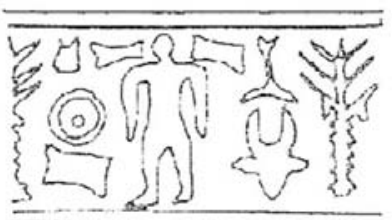

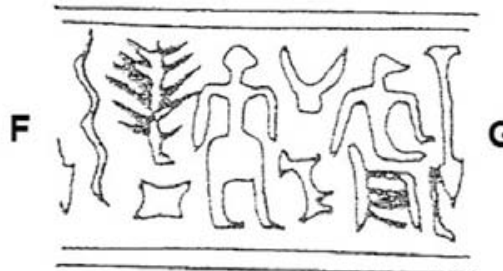

G

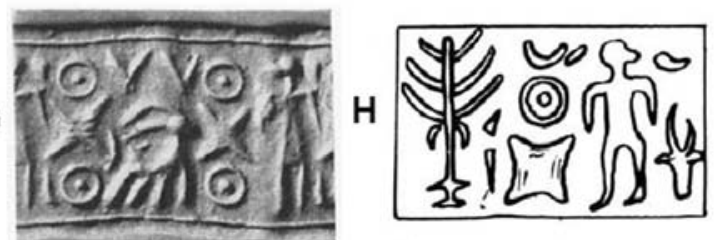

I
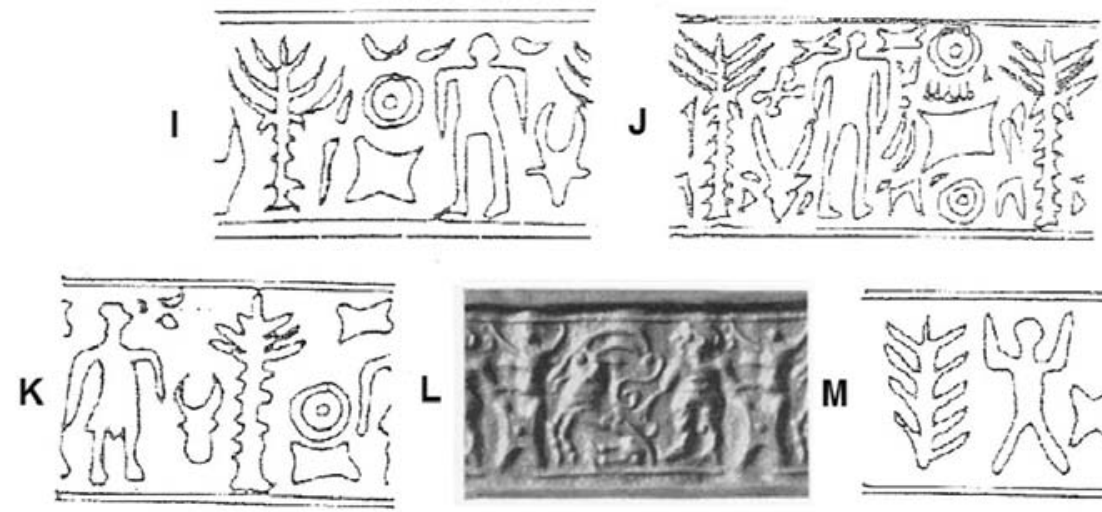

L
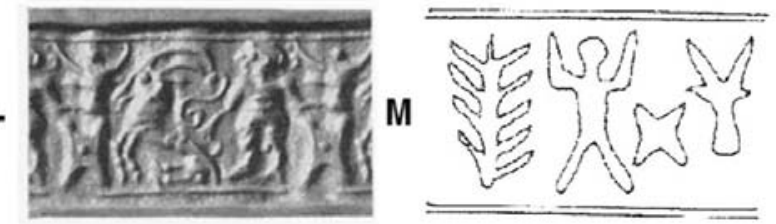

Figura 5: Improntas de cilindros-sellos procedentes de Chipre.

lingotes chipriotas (quizás deberíamos de decir siriochipriotas) son interpretados por nosotros como altares rodeados de todos los elementos relacionados con la práctica cultual recogidos en las piezas sirias. Así, junto a los altares vuelven a aparecer las asherah y los cráneos o cornamentas vinculables tanto con los hallados en los santuarios de Enkomi como en los cilindros-sellos hallados en la actual Ras Shamra. Un elemento sí que querríamos destacar de todos los aparecidos en los ejemplares que conocemos. Se trata de una figura formada por tres círculos concéntricos, interpretable como un signo astral al igual que el conjunto de puntos o el signo con doble contorno de los ejemplares ugaríticos. Pero queremos llevar más allá esta idea y especificar que podríamos estar ante una representación solar o lunisolar según los casos que se manifestaría en todas las ocasiones encima del altar, y cuando no lo hace no aparece en ninguna otra parte de los cilindros-sellos. Así, el ejemplar procedente de Kourion (Fig. 5, A) tiene sobre el altar la imagen de un posible sol con un cuarto lunar, mientras que los demás muestran tan sólo a la figura solar sobre el altar.
Quizás el más interesante para nuestros resultados sea el ejemplar hallado en Hala Sultan Tekke (Fig. 5, $\mathrm{J})$, sin duda el que más elementos presenta y el único en el que apreciamos una serie de triángulos entre el altar y el símbolo solar que interpretamos como las llamas que intentan reflejar el holocausto del sol, de ahí que podamos observar bajo el altar otro símbolo solar, probablemente de resurrección. En la misma línea se interpretaron las líneas grabadas en una de las caras de un vaso de mármol procedente de Sidón y datable en torno al s. IV a. C. como la representación del fuego que testimonia la muerte por combustión del dios sobre el altar, tratándose de un ejemplo más que ha sido relacionado con la muerte y resurrección de la divinidad baálica a través de una hipótesis astronómica y no relacionada con los ciclos de la naturaleza (Escacena, 2009, 109). De igual modo, estas figuras de tipo astral aparecen sobre y bajo altares taurodérmicos en dos cilindros-sellos procedentes también de Chipre, destacando entre su glíptica un animal cornudo con un betilo sobre su lomo, representación de la divinidad anicónica de tradición semítica, lo que da un carácter 
más religioso si cabe a estas escenas, alejándolas de las interpretaciones metalúrgicas y pecuarias (Kenna, 1967, 577).

Así, entre las características de este tipo de rituales visibles en los cilindros-sellos de Ugarit observamos algunas peculiaridades adscribibles al culto practicado en santuarios chipriotas como el de Enkomi, mencionado anteriormente. El primero tiene relación con los huesos hallados en la estancia principal del templo del "dios del lingote": se trata de una serie de cráneos de bóvidos que no conservan parte del esqueleto en la zona posterior y que dada esta característica ha servido a los investigadores para otorgarles un uso como máscaras rituales que serían utilizadas por los sacerdotes durante las liturgias. Este ejemplo nos remite a los cuernos que lleva sobre la cabeza la figura sedente del segundo de los cilindros-sellos aquí analizados procedente de Ugarit. Quizás podamos afirmar con este paralelo que en este cilindro-sello estamos ante un sacerdote ataviado con una máscara de este tipo durante el ritual sacrificial. De igual modo, varias veces aparecen representados bucráneos y elementos que podrían ser relacionados con cornamentas, acaso en conexión una vez más con los ejemplos citados procedentes tanto de los cilindros-sellos chipriotas como de los santuarios de la misma isla.

Junto a estas representaciones también se recogen, como en los ejemplares ugaríticos, asherah junto a los altares, lo que nos remite a un ambiente semítico claramente relacionado con el mundo cananeo. La dualidad altar-asherah dispone de multitud de referencias textuales en la Biblia a propósito de los "ignominiosos" altares baálicos (Jeremías 11, 13). Pero aparte de estas referencias escritas también tenemos ejemplos documentados tanto entre la toréutica oriental como entre los hallazgos de la Península Ibérica (Escacena y Coto, 2010; Gómez Peña, 2010).

A la luz de estas representaciones podríamos reinterpretar los dos smiting gods comentados anteriormente. Hasta la fecha, tanto al "dios del lingote" como a su paredro de la colección Bomford se les ha identificado con sendas divinidades protectoras del trabajo de las minas y de la fertilidad de las mismas, lo que denota la clara identificación de las bases sobre las que se asientan las divinidades con los tan reiterativos lingotes de forma taurodérmica entre la bibliografía especializada. Sin embargo, a tenor de la hipótesis elaborada por J. L. Escacena (2007, 628, fig. 11), se puede interpretar que ambas figuras son la manifestación de la divinidad sobre el altar, lo que indefectiblemente obliga a relacionarlas con los símbolos astrales aparecidos en los cilindros-sellos. A este respecto creemos que la propuesta metodológica que utilizamos resulta válida, pues tanto la forma de los altares, las representaciones holocáusticas visibles junto a ellos, su carácter exento y su relación con símbolos astrales de carácter lunisolar encajan perfectamente en los cilindros-sellos analizados y, por extensión, con los smiting gods estudiados.
Todo este conjunto de símbolos cobra más coherencia como un todo común a la mayoría de los pueblos semitas, incluido el cananeo, si tenemos en cuenta la siguiente cita bíblica a propósito de los tabúes identitarios de la población hebrea:

\begin{abstract}
"Atiende bien a lo que te mando hoy: Yo arrojaré de ante ti al amorreo, al cananeo, al geteo, al fereceo, al jeveo y al jebuseo. Guárdate de pactar con los habitantes de la tierra contra la cual vas, pues sería para vosotros la ruina. Derribad sus altares, romped sus cipos, y destrozad sus aseras. No adores otro Dios que yo, porque Yave se llama celoso, es un Dios celoso. No pactes con los habitantes de esa tierra, no sea que al prostituirse ellos ante sus dioses, ofreciéndoles sacrificios, te inviten, y comas de sus sacrificios, y tomes a sus hijas para tus hijos, y sus hijas, al prostituirse ante sus dioses, arrastren a tus hijos a prostituirse también ellos ante sus dioses.

No te harás dioses de metal fundido" (Éxodo 34: 11-17) (Nácar y Colunga, 2008, 97).
\end{abstract}

Desde nuestro punto de vista, tenemos en estas representaciones la plasmación de la existencia en momentos del II milenio a. C. de los altares taurodérmicos que dieron origen a los peninsulares por poblaciones de filiación semita. Así, revisando los contextos en que han aparecido estas aras en España con datación en la primera mitad del I milenio a. C., observamos cómo los tres únicos ejemplares hasta el momento (El Carambolo, Caura y Malaka) guardan estrechas similitudes con los elementos representados en los cilindrossellos (Fig. 6). No ya sólo por la forma de los propios altares, sino por su orientación astronómica, las marcas circulares ennegrecidas en su interior, la existencia de huecos para las asherah al lado de los ejemplares de El Carambolo y de Caura, y lo que se ha sabido más recientemente, la constatación de sebo de intestino de oveja o de cabra entre las huellas de combustión aparecidas en la superficie del altar de Caura (Escacena y Coto, 2010, 163).

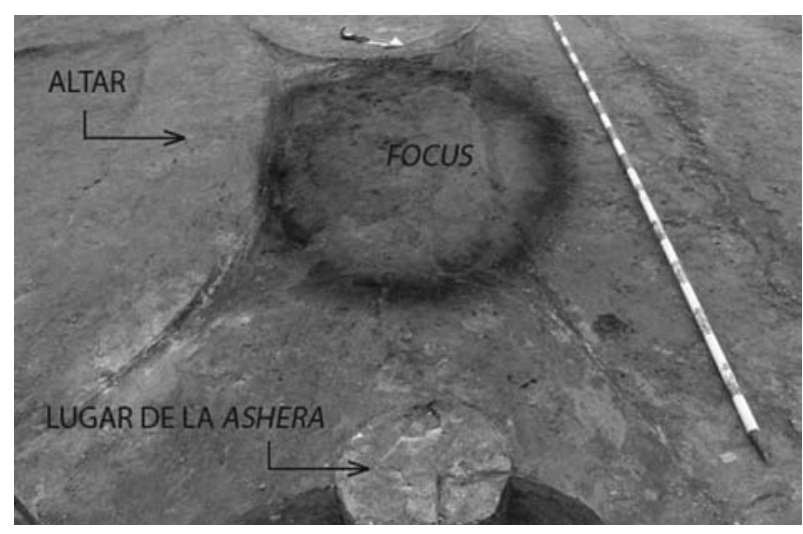

Figura 6: Altar del Carambolo III con la huella de una posible antigua asherah colmatada con barro amarillento en su nueva fase (Escacena y Coto, 2010, 171). 


\section{LOS ALTARES TAURODÉRMICOS ASIRIOS}

No obstante, si bien los ejemplares ugaríticos y chipriotas comentados anteriormente suponen los paralelos más cercanos con los que relacionar a los altares andaluces, no son los únicos testimonios arqueológicos con los que contamos en el Próximo Oriente, pues las pinturas de varios palacios del área asiria fechables entre los siglos IX y VII a. C. guardan estrechas similitudes con todo el elenco de elementos que venimos analizando.

Ya comentamos anteriormente que los primeros en relacionar con la piel de bóvido trabajada ciertas escenas aparecidas en pinturas procedentes de los palacios asirios de Khorsabad (antigua Dur Sharrukin), Arslan-Tash (antigua Hadatu) y Tell Ahmar (antigua Til-Barsip) fueron E. Kukahn y A. Blanco (1959, 42), haciéndose eco de estos ejemplares hace escasos años J. Maier (2003, 100) y J. L. Escacena (2006, 137-138). Las escenas aportadas hasta ahora en la bibliografía están compuestas en la mayoría de los casos por toros con la cabeza mirando hacia abajo en lo que J. Maier interpreta como una posición de embestir que muestra la potencia del animal (Maier, 2003, 100). Sin embargo, en nuestro estudio hemos podido ampliar el número de ejemplares, hallando toros y cabras con las rodillas postradas en el suelo, por lo que interpretamos las diferentes posturas como indicativo de respeto e incluso de sumisión holocáustica ante una figura central. Es precisamente esta figura en la que queremos poner especialmente nuestra atención. Se trata de un cuadrado con las esquinas alargadas que recuerda en su forma a los altares taurodérmicos, a lo que se suma una zona central que se correspondería con la imagen astral de la divinidad como más adelante nos disponemos a explicar, lo que en los altares de barro del suroeste peninsular vendría a ser el focus, que no es más que la huella arqueológica del animal sacrificado para la deidad y en algunos casos de la propia divinidad tras su muerte por combustión.

Esta somera descripción formal es aplicable a la inmensa mayoría de los ejemplos encontrados por nosotros hasta el momento, excepción hecha de algunos ejemplares que no presentan el círculo central. Procedente de Nimrud (la Kalkhu asiria) hemos encontrado nuevos ejemplos hasta ahora no documentados entre la historiografía protohistórica peninsular. Se trata de frescos pintados en las habitaciones $\mathrm{A}, \mathrm{B}$ y $\mathrm{C}$ de las denominadas upper chambers excavadas por A. H. Layard al sur del palacio noroccidental (Fig. 7), quien detallaba al respecto lo siguiente:

"The painted ornaments were elaborate and graceful in design. The Assyrian bull was frequently portrayed, sometimes with wings, sometimes without. Above the animals were painted battlements, similar to those of castles, as represented in the sculptures. Below them, forming a kind of cornice, were squares and circles tastefully arranged; and more elaborate combinations were not wanting" (Layard, 1849, II, 15-16).

Precisamente A. H. Layard relaciona estas decoraciones con las encontradas en el palacio de Adad-Nirari III, también en Nimrud. Sin embargo, Adad-Nirari III construyó varios palacios sin que se especifique en cuál de ellos estaban dichas pinturas. Las correspondientes a las habitaciones A, B y C de Nimrud alternan tanto figuras circulares identificadas con rosetas de doce pétalos en torno a un círculo central, como figuras taurodérmicas entre toros alados y toros no alados con las rodillas hincadas en el suelo (Albenda, 2005, 15); además de estas pinturas, también es posible que estemos ante otros ejemplares cuando P. Albenda denomina "cuadrado en forma de cojín" a los elementos pintados de un edificio a las afueras de la ciudad también de época de Adad-Nirari III:

"On the east wall, within the framing lines of the
painting, the center panel consists of a design of
bulls, heads turned back, on either side of a circle.
The bodies of the bulls are red; the geometric de-
signs are cobalt blue and white, all with a black out-
line. On either side of the central panel, a cushion-
shaped square completes the painted decoration that
extended across the length of the east wall" (Alben-
da, 2005, 20).

Muy probablemente también de época de este mismo rey asirio sea la decoración de la pared de la cella de un templo asirio hallado en Tell al-Rimah (antigua Qattara) en la que se observa un friso que alterna figuras de forma taurodérmica (cushion-shaped squares en palabras de P. Albenda) y círculos junto a criaturas aladas compuestas de las que no especifica más (Albenda, 2005, 21). Otro caso, éste sí mencionado en estudios anteriores (Maier, 2003; Escacena, 2006), es el procedente de Khorsabad (antigua Dur Sharrukin). En dicho complejo arquitectónico, adornando una de las paredes de la sala 12 de la residencia $\mathrm{K}$ se hallaron restos de pintura en las que se apreciaban genios de rodillas ante una figura con varios círculos concéntricos en su interior y en otro nivel toros afrontados ante una figura taurodérmica con círculos en su interior y brotes al interior de cada esquina de la misma (Loud y Altman, 1938, figs. 89-90) (Fig. 8). Un nuevo ejemplo procedente de una habitación real de Arslan Tash (antigua Hadatu) y fechable entre fines del siglo VIII y el VII a.C. muestra en ritmo alterno círculos concéntricos y pieles de toro trabajadas con brotes en las esquinas (Albenda, 2005, 25) (Fig. 9). De nuevo la misma asociación de elementos se repite en una pintura hallada en la sala del trono S5 de Fort Shalmaneser en Nimrud (antigua Kalkhu), esta vez alternándose taurodermos y círculos concéntricos sin que dentro de aquéllos aparezca nada. Nos encontramos por tanto ante una de las representaciones más simples de todas las encontradas hasta el momento (Fig. 10). Bajo estos símbolos aparece una corte de asistentes vestidos a la manera asiria y portando una espada (Albenda, 2005, 

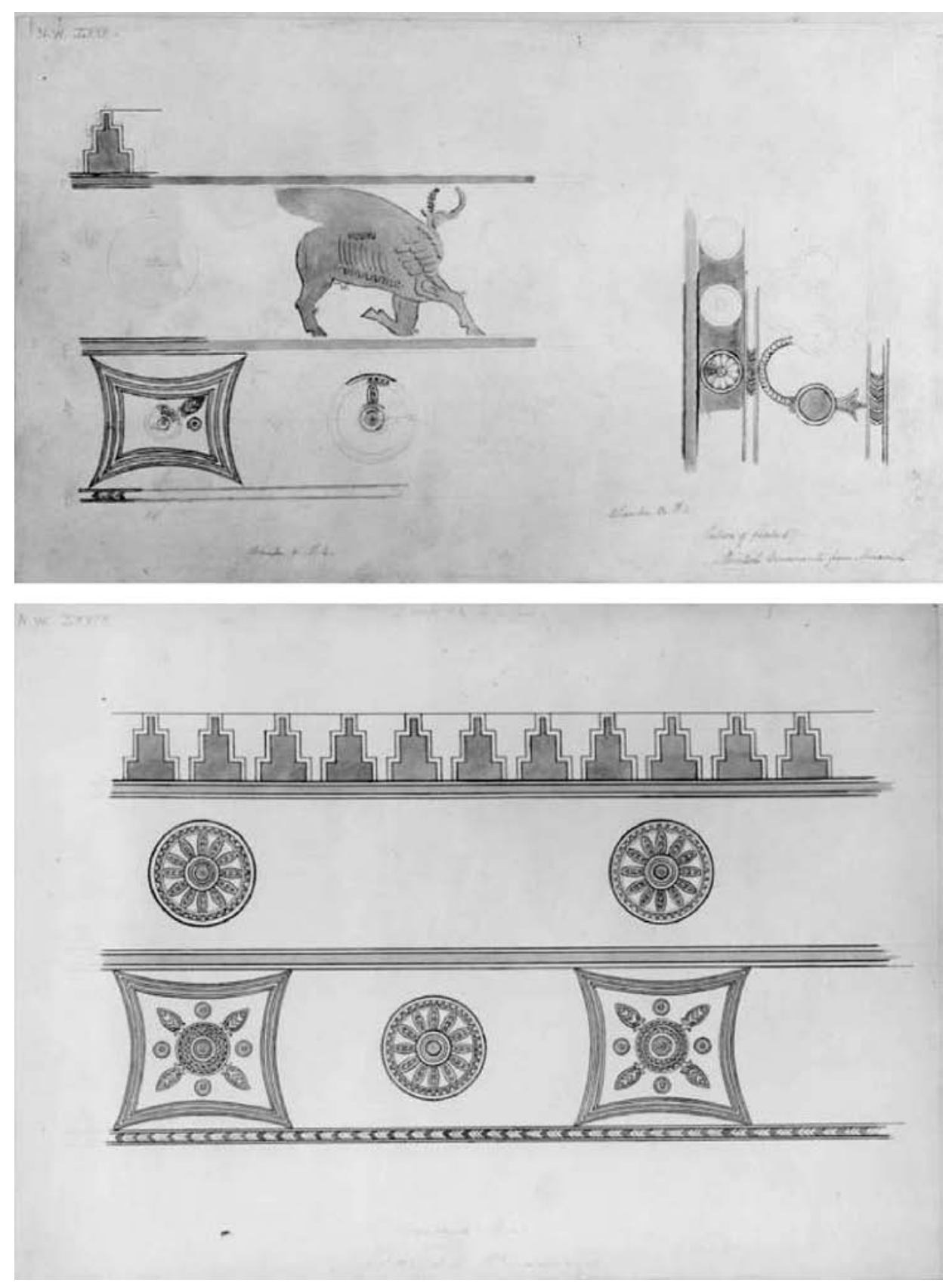

Figura 7: Dibujos de la habitación superior A (arriba izq.) y de la habitación superior B (arriba der.) (Albenda, 2005, 16). Dibujos de la habitación superior A (abajo) (Albenda, 2005, 16).

30). Pero no sólo aparece esta figura junto a su paredra de círculos concéntricos, ni sólo entre toros, sino también entre cabras como mencionamos anteriormente. Es el caso de la pintura aparecida en la denominada habitación 26 del palacio de Tell Ahmar (antigua TilBarsip), un largo corredor en el que en sus paredes se ha representado a un par de cabras postrando en tierra una de sus rodillas delanteras afrontadas hacia un símbolo taurodermo con un círculo en su interior y brotes en sus cuatro esquinas (Albenda, 2005, 35) (Fig. 11). De igual modo en la habitación 25 del mismo palacio también aparecen en los extremos de una decoración en la que dos genios femeninos flanquean con brotes a un conjunto de círculos concéntricos (Albenda, 2005, 37) (Fig. 12). Otra novedad procede de la habitación 46 , en la que nuevamente dos genios aparecen arrodillados frente a una nueva piel de toro sin que los restos conservados puedan indicar qué portan ante el símbolo, si bien es posible que nuevamente ofrezcan algún tipo de brote como el que presenta en su interior junto a un círculo central (Albenda, 2005, 40) (Fig. 13). Por otra parte, un nuevo ejemplo procede del corredor 21, un largo pasillo que conecta los patios $\mathrm{B}$ y $\mathrm{C}$ donde se pintaron una serie de símbolos taurodermos con toros afrontados con sus patas delanteras estiradas y la cabeza una vez más agachada (Albenda, 2005, 44) 


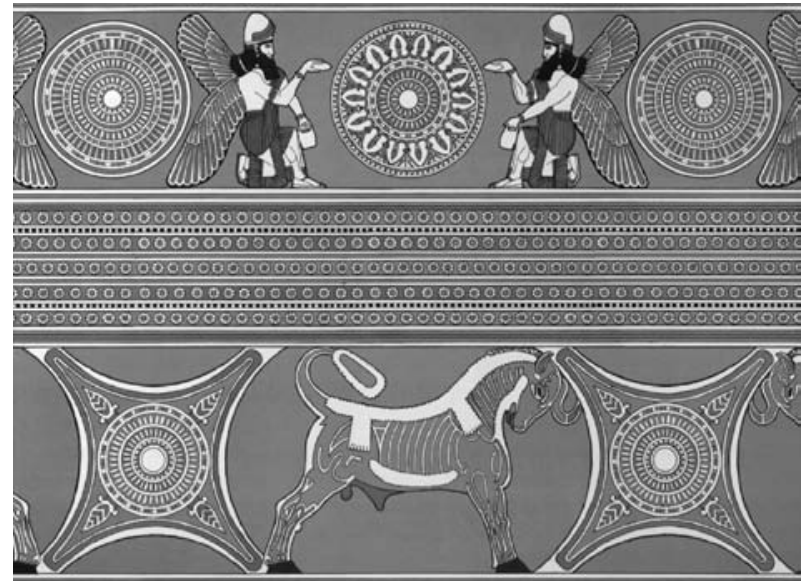

Figura 8: Decoración de las paredes de la sala 12 de la residencia K (Loud y Altman, 1938, fig. 90).

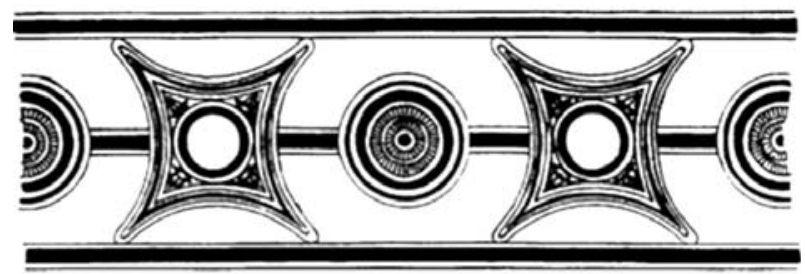

Figura 9: Decoración de las paredes de una de las habitaciones reales de Arslan Tash (Albenda, 2005, 25).

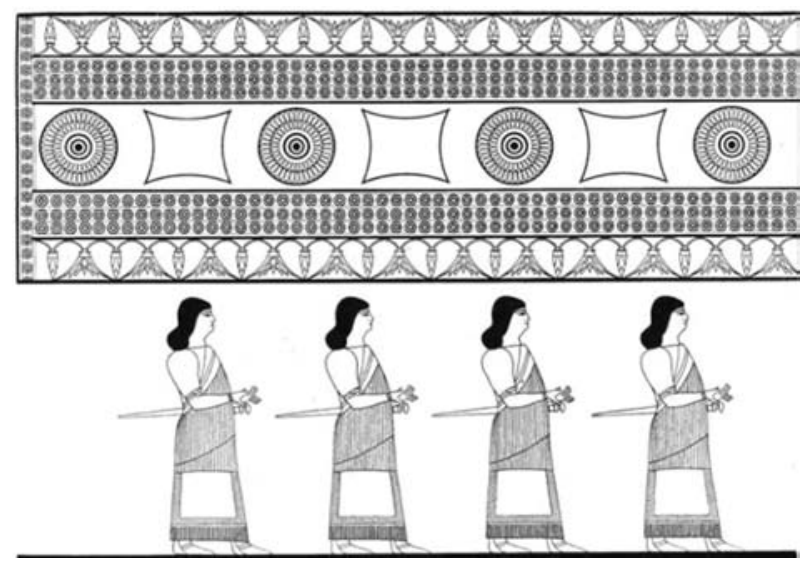

Figura 10: Decoración de las paredes de la sala del trono S5 de Fort Shalmaneser en Nimrud (Albenda, 2005, 30).

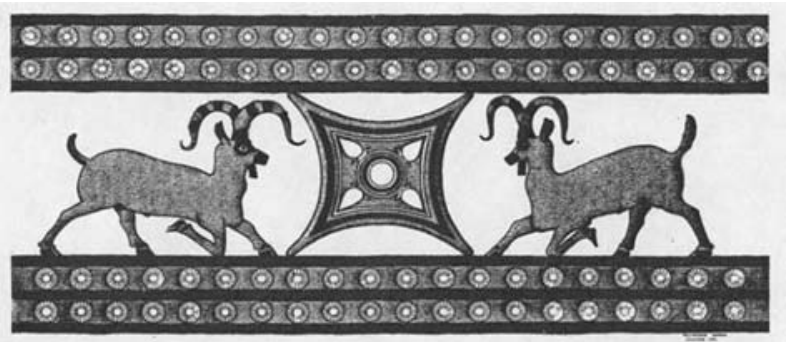

Figura 11: Decoración de las paredes de la habitación 26 del palacio de Tell Ahmar (Albenda, 2005, 35).
(Fig. 14). Entendemos nuevamente que más que estar en actitud de embestir se encuentran rindiendo respeto o preparados para el holocausto ante un símbolo de corte divino. Procedentes de las habitaciones 22 y 24 encontramos dos de los ejemplos más simples, que nos recuerdan bastante a las pinturas de la sala del trono S5 de Fort Shalmaneser (vid. supra). Se trata una vez más del mismo símbolo de apariencia tauroderma pero esta vez presentando sólo un doble contorno (sala 22), y un doble contorno con tres círculos concéntricos en su interior (sala 24) (Albenda, 2005, 46) (Fig. 15).

Viendo todas estas escenas, afortunadamente recogidas en una buena síntesis sobre las mismas por P. Albenda, quizás sea la última de las comentadas la que por su simpleza y la falta de elementos que la acompañen, tanto dentro como a los lados, permitan ver con más claridad el paralelo entre ellas y los altares. A este respecto, la metodología seguida ve como puntos a favor su forma con las esquinas alargadas, su doble contorno y la presencia de un círculo central que si bien no representa al focus, sí representa a la divinidad. Con respecto a este último aspecto, nuestra interpretación entiende que si los círculos concéntricos son aceptados por los especialistas como representación de una divinidad, lo cual es bastante probable dado que los genios que la flanquean se arrodillan ante ella para ofrecerle incienso o brotes, el mismo símbolo dentro del altar debe de entenderse como la representación de la divinidad antes o después de su muerte y resurrección en el ara, lo que cobra más fuerza aún si vemos cómo se trata del mismo tipo de círculo y con los mismos detalles el que se encuentra pintado tanto dentro del taurodermo como fuera de éste en dos frisos procedentes de Khorsabad y citados anteriormente (Fig. 8). De ser cierta nuestra interpretación, sería el mismo caso que en las representaciones de cilindros-sellos chipriotas, donde los círculos concéntricos son la representación astral de la divinidad sobre el altar, lo mismo que los smiting-gods lo son en su aspecto humanizado. Así, el que todos estos símbolos taurodermos sean expresiones de altares parece más claro todavía si interpretamos a los toros de pie con la cabeza agachada, y a los toros y cabras arrodillados ante la piel de toro (nunca ante los círculos concéntricos solos), como víctimas

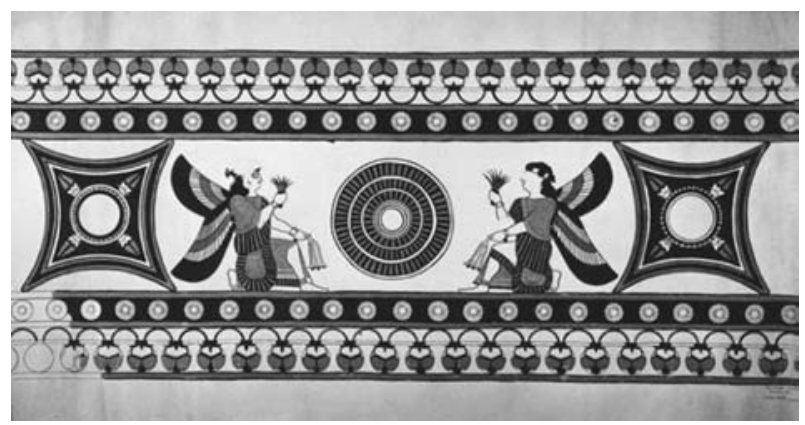

Figura 12: Decoración de las paredes de la habitación 25 del palacio de Tell Ahmar (Albenda, 2005, 37. 


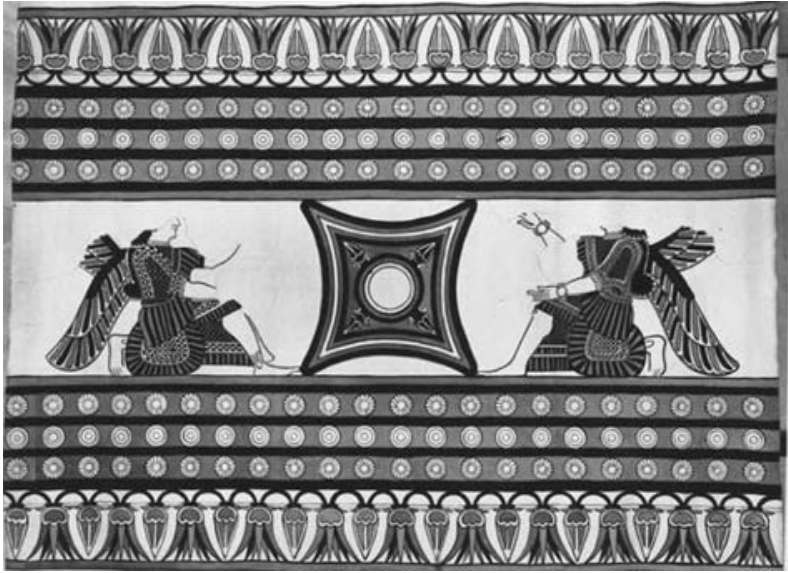

Figura 13: Decoración de las paredes de la habitación 46 del palacio de Tell Ahmar (Albenda, 2005, 40).

próximas al sacrificio. No obstante, resulta imposible poder otorgar con claridad una advocación a esta figura, toda vez que no tenemos paralelos claros más allá de estas pinturas. Tan difícil resulta hablar de ellas que en el exhaustivo estudio que P. Albenda realiza sobre éstas no les dedica un apartado como hace con todos y cada uno de los elementos aparecidos en los frescos asirios, hipotetizando únicamente en sus conclusiones que podría ser un símbolo de las cuatro partes del mundo conquistadas por los gobernadores asirios (Albenda, 2005, 134), para lo cual no explica en ningún lugar por qué se aventura a lanzar tal suposición. ¿Qué sentido tiene que los genios arrodillados ofrezcan brotes a las cuatro partes del mundo? ¿Y los toros y cabras postrados ante él?

Todos estos elementos, siendo relacionados con los cilindros-sellos semitas y con los altares peninsulares cobran sentido en su conjunto y explican mejor cada uno de los elementos por separado que la aventurada interpretación de P. Albenda. Pero especialmente significativa para nuestra propuesta es la interpretación que de las tradicionalmente denominadas "paletas de ungüentos" han hecho recientemente J. L. Escacena y M. Coto. En dicho estudio, ambos autores plantean la posibilidad de estar no ante paletas de cosméticos, sino ante pequeños altares portátiles cuyas representaciones grabadas en el marfil estarían cargadas de un simbolismo cultual. Estas láminas de marfil con pocillo central presentan a ambos lados de éste imágenes con una semiótica ritual que permite relacionar estas placas con las pinturas asirias. En el artículo, los firmantes reconocen las debilidades de la hipótesis que ve en estas piezas paletas de tocador porque los ejemplares orientales no tienen dos aletas como sí presentan éstas, del mismo modo que ningún análisis ha demostrado que tengan restos de pigmentos por ningún lado de su superficie. En cambio, la hipótesis de J. L. Escacena y M. Coto (2010), tomando como paralelo las pinturas asirias, deja para nosotros a las claras que unos y otros tienen paralelos iconográficos bastante cercanos como para pensar en una relación

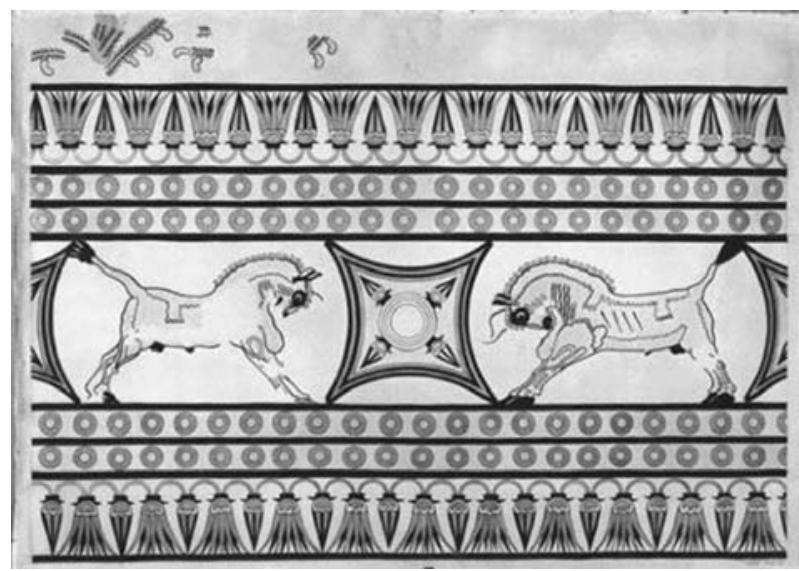

Figura 14: Decoración de las paredes del corredor 21 del palacio de Tell Ahmar (Albenda, 2005, 44).

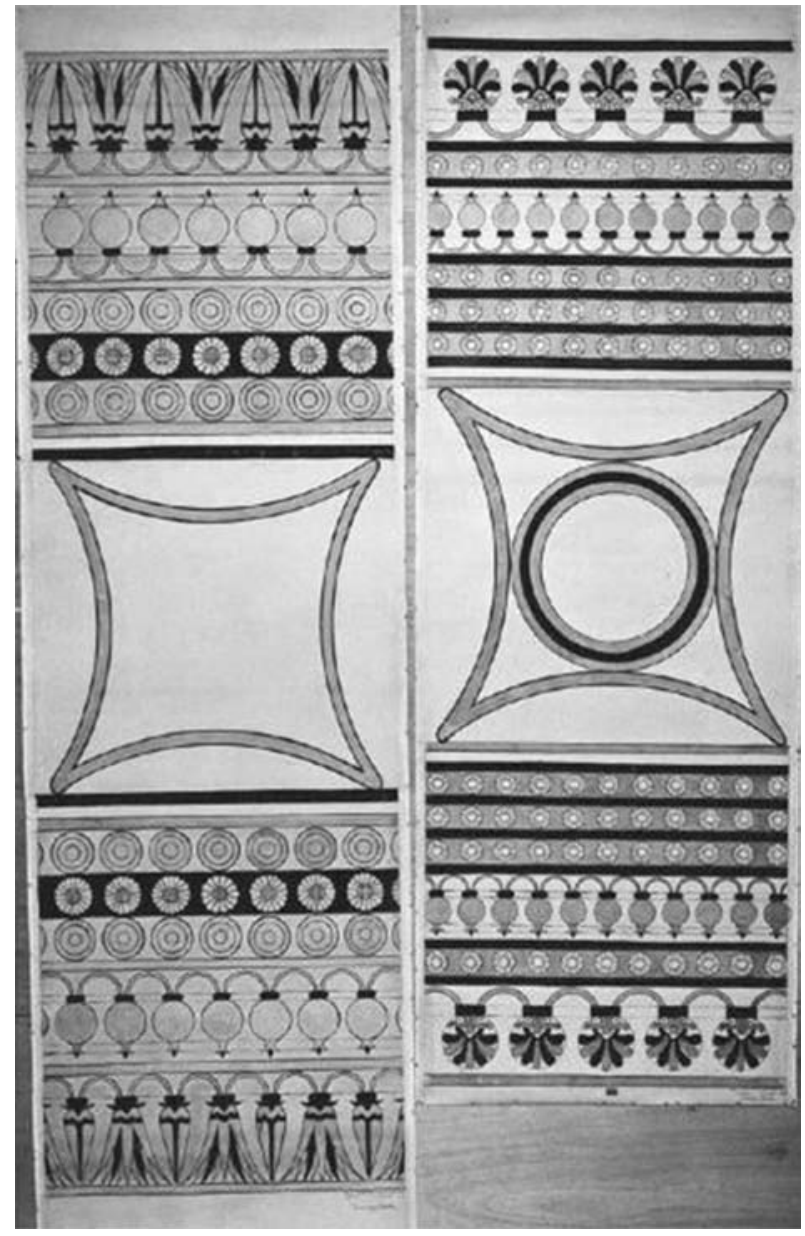

Figura 15: Decoración de las paredes de las habitaciones 22 (izquierda) y 24 (derecha) de Tell Ahmar (Albenda, 2005, 46).

semiótica del mismo tipo: animales para el sacrificio, brotes en las esquinas del focus, personajes protectores y profilácticos, cenefas de flores abiertas y cerradas con simbología de resurrección cíclica, etc. Para ello, remitimos al lector al artículo para que pueda bucear por sí mismo entre sus imágenes y apreciar la cantidad de elementos similares entre ambas plasmaciones, la 
pictórica y la ebúrnea, a la que queremos sumar una que se les escapó a los autores: el paralelismo entre la procesión de personajes con túnica en el ejemplar AL.1 de Alcantarilla (Escacena y Coto, 2010, 169, fig. 19) y la procesión de una corte del mismo tipo en la pintura del S5 de Fort Shalmaneser en Nimrud (antigua Kalkhu) (Fig. 10).

\section{LA CONTINUIDAD DEL SÍMBOLO EN EL MUN- DO ESCITA}

Pero el mismo símbolo con sus esquinas alargadas y cuatro brotes en el interior lo encontramos igualmente en el área de influencia escita a partir del siglo IV a. C. Se trata de una pieza que tuvimos la ocasión de contemplar de primera mano con motivo de la exposición El oro de los argonautas. Tesoros del Museo Nacional de Georgia en el Museo Arqueológico de Sevilla durante 2010. El objeto en cuestión es un candelabro de seis mechas con orificio central, de $25 \mathrm{~cm}$ de diámetro ( $\mathrm{n}^{\mathrm{o}}$ de inv. 07:1-07/323), hallado en un depósito en el santuario de Vani (Georgia) en 2007 y fechable en el siglo II a.C. (Almagro-Gorbea, 2010, 137) (Fig. 16). Somos conscientes del lapso temporal entre los últimos ejemplares pintados en salas asirias a principios del siglo VII a.C. y la figura grabada sobre la frente de los elefantes representados en este candelabro del siglo II a.C., por lo que se requiere prudencia a la hora de conectar los posibles significados de esta pieza con las representaciones asirias, ya que el hallazgo de Vani nos remite a una zona externa al área de aparición de los ejemplares más antiguos, en un momento posterior y con tradiciones diferentes, por lo que el símbolo, de ser el mismo, puede tener una lectura distinta. Pero a pesar de ello, ambos elementos son idénticos y su simbología tiene más conexiones que nos disponemos a detallar a continuación.

La primera de ellas, y desde el punto de vista arqueológico la que más acerca a estas dos representaciones idénticas, se trata de un ara de piedra hallada en la región de Baite, situada entre los mares Aral y Caspio (Kazajistán) (Fig. 17, A). Ésta, que presenta perfil taurodérmico y doble contorno realizado por la depresión central que sirve de gran contenedor, presenta pequeñas cazoletas en cada una de las esquinas que han sido interpretadas como receptáculos de líquidos utilizados en los rituales. Su paralelo más evidente en la Península Ibérica es el altar de Villaricos (Fig. 17, B), fechado en el Hierro II. Pero lo que más nos llama la atención, y por ello queremos remarcar este hecho, es que para quienes han estudiado tanto esta pieza como el resto de estructuras halladas en los santuarios de entre los siglos IV-II a.C. (momento en que puede datarse la pieza), su análisis revela que muchos de estos edificios tienen una tipología hasta ahora desconocida en la región esteparia euroasiática (Olkhovskiy, 2000). Así, las estatuas de guerreros encontradas en éste y en otros santuarios de la meseta de Oustiourt (o Ustyurt), reflejan la continuidad de una tradición, a caso sármata, procedente del oeste (Lebedynsky, 2006, 86-87), si bien sus excavadores se resisten a defender esta hipótesis ya que estos hallazgos se han realizado al este del mar Caspio. No obstante, ejemplos como los de Vani, al oeste de dicho mar, pueden poner en relación ambas zonas geográficas a través del nomadismo de las poblaciones existentes en la zona, así como acercar más en el tiempo este símbolo en ambas tradiciones, la asiria y la escita.

No resultaría raro, a la luz de todos estos datos, que el altar y la abstracción de la divinidad fuesen el mismo símbolo, ni tampoco que apareciera en la frente de un elefante, como se aprecia en el candelabro. A este respecto resulta interesante observar que la forma grabada sobre la frente de estos animales presenta unas cadenas que bien podrían indicarnos que se engalanaba a éstos con joyas como la aquí tratada, cuya forma insistimos presenta un doble contorno y cuatro brotes en su interior sin presencia aparente de círculo central. ¿Podríamos relacionar como paralelos inconexos la simbología de esta forma en el hallazgo de Vani (Georgia) con los frontiles de El Carambolo (Camas, Sevilla) (Fig.

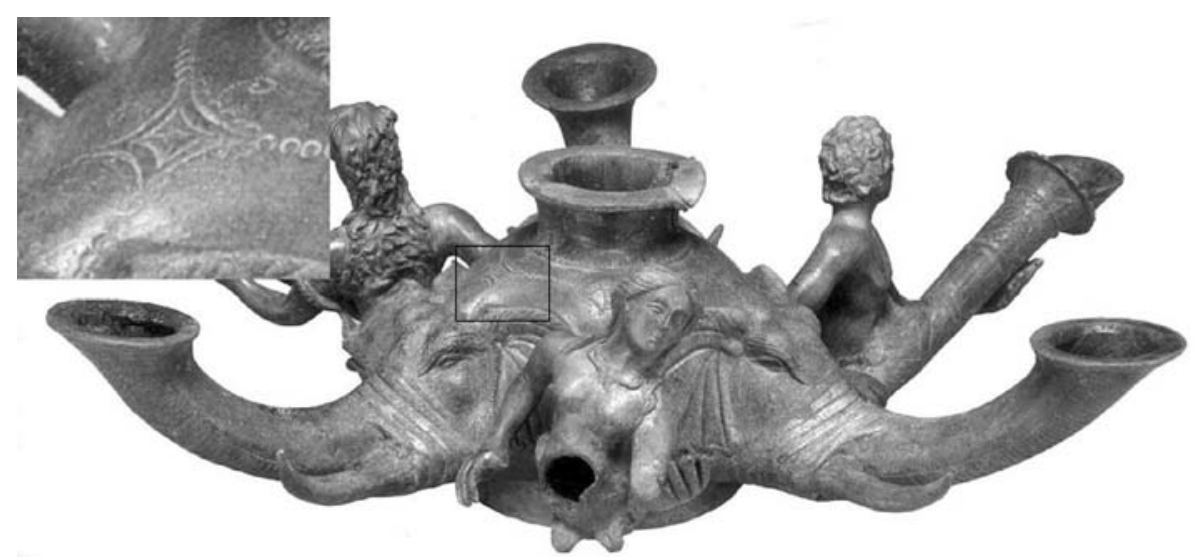

Figura 16: Candelabro de seis mechas hallado en Vani (Georgia). En las frentes de los elefantes se grabó el mismo símbolo representado en las pinturas asirias (Almagro-Gorbea, 2010, 137). 

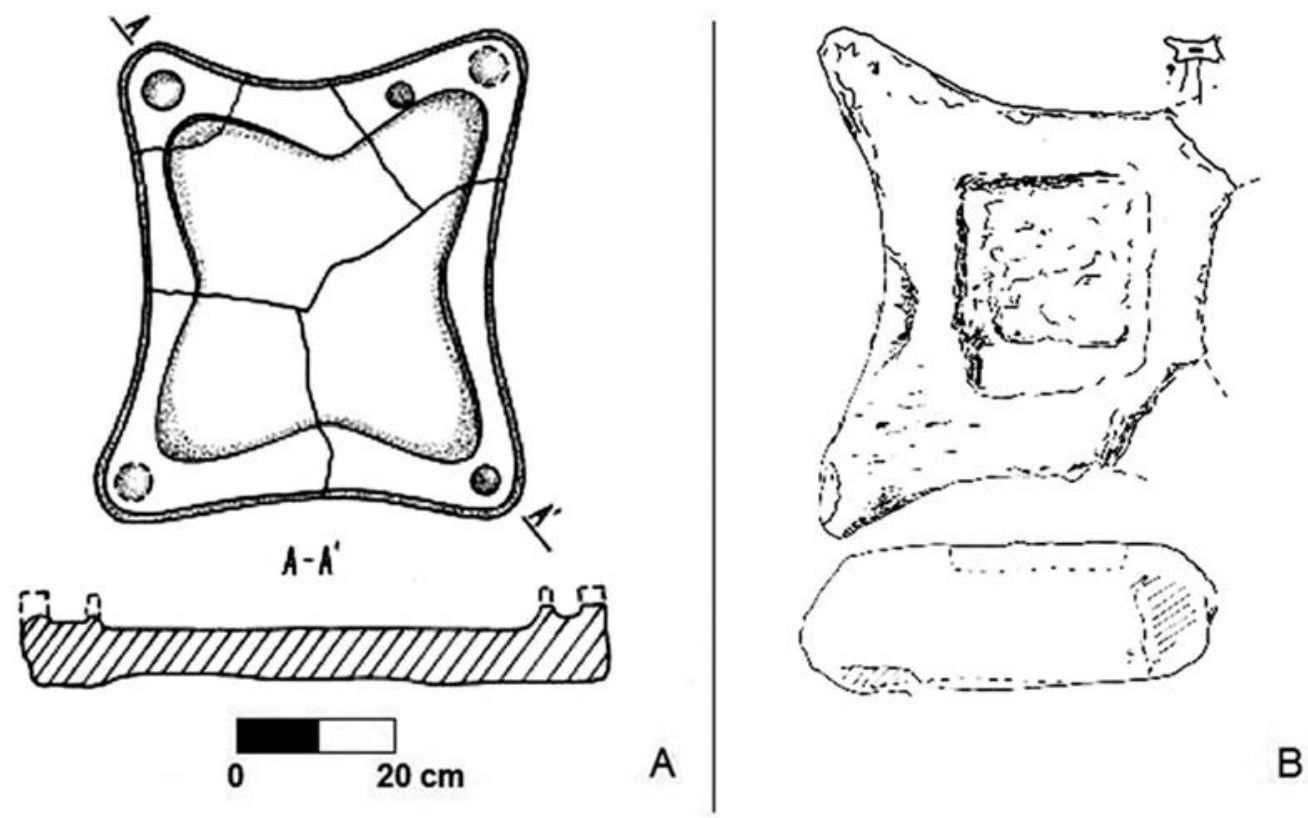

Figura 17: A) Altar de piedra de Baite III (Kazajistán) (Olkhovskiy, 2000, 42); B) Altar de piedra púnico procedente de Villaricos (Almería).

18) o los de esculturas como las de Monforte del Cid (Fig. 19) y Villajoyosa (Fig. 20) (ambas en Alicante)? ¿Y al altar de Baite III con el ejemplar de Villaricos (Almería)? No proponemos en ningún momento que la relación sea directa, ni por ser unos descendientes de los otros ni por servirse de inspiración, sino que pretendemos llamar la atención sobre la posibilidad de que ambas manifestaciones fueran ramas de un hipotético tronco común de filiación levantina.

Así, en ambos casos el carácter de potencia con que se puede relacionar al símbolo taurodérmico por aparecer en la testuz de toros y elefantes le otorga al símbolo connotaciones de protección. A este respecto, el carácter apotropaico que venimos defendiendo en estas líneas para el detalle del candelabro escita tiene eco entre otros textos en un pasaje de Luciano (siglo

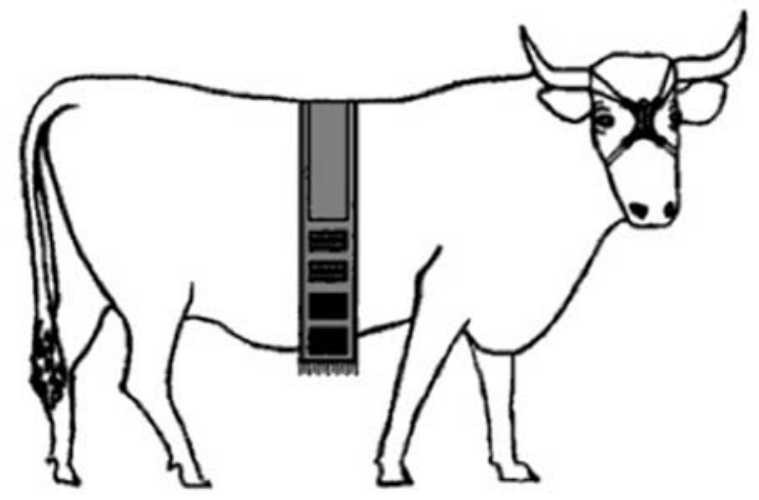

Figura 18: Propuesta de colocación de algunas de las piezas del tesoro de El Carambolo con el frontil en la testuz del bóvido (Amores y Escacena, 2003, 60).
II d. C.). Es necesario entender este fragmento como una costumbre escita que se inserta dentro de la tradición acabada de comentar y resalta la importancia de la trascendencia de este símbolo pasado incluso el cambio de era:

\begin{abstract}
"Nuestra costumbre relativa a la piel es la siguiente: cuando un hombre ha sido ofendido por otro y quiere vengarse, pero ve que por sí mismo no tiene capacidad de lucha suficiente, sacrifica un toro, trocea la carne y la cuece, y a continuación él mismo se extiende la piel en el suelo y se sienta sobre ella, con las manos en la espalda, como los que están atados por los codos. Ésta es para nosotros la más significativa petición de ayuda. Una vez servidas las carnes del toro, se acercan los familiares y también si algún otro lo desea, toma cada uno una porción de carne y entonces pone el pie derecho en la piel y promete, de acuerdo con sus posibilidades, uno que proporcionará cinco jinetes a quienes no se dará comida ni soldada, otro diez, otro más, otro los hoplitas que pueda, el más pobre se ofrece él sólo. Así se reúne a veces en la piel una gran fuerza y este ejército es tan seguro para la resistencia como invencible ante el enemigo, pues que está juramentado, pues el hecho de poner el pie en la piel es un juramento" (Luciano, To. 47-48; trad. de Zaragoza, 1990, 325).
\end{abstract}

A propósito de este texto se ha expresado M. C. Marín defendiendo la hipótesis de que la piel de bóvido actúa aquí como un símbolo en torno al cual sellar los pactos (Marín, 2006, 46). Es innegable que en muchas ocasiones la piel va ligada a los tratos, pero si se le atribuye un carácter apotropaico puede interpretarse su papel en este texto del mismo modo en que lo hace G. Dumézil: 


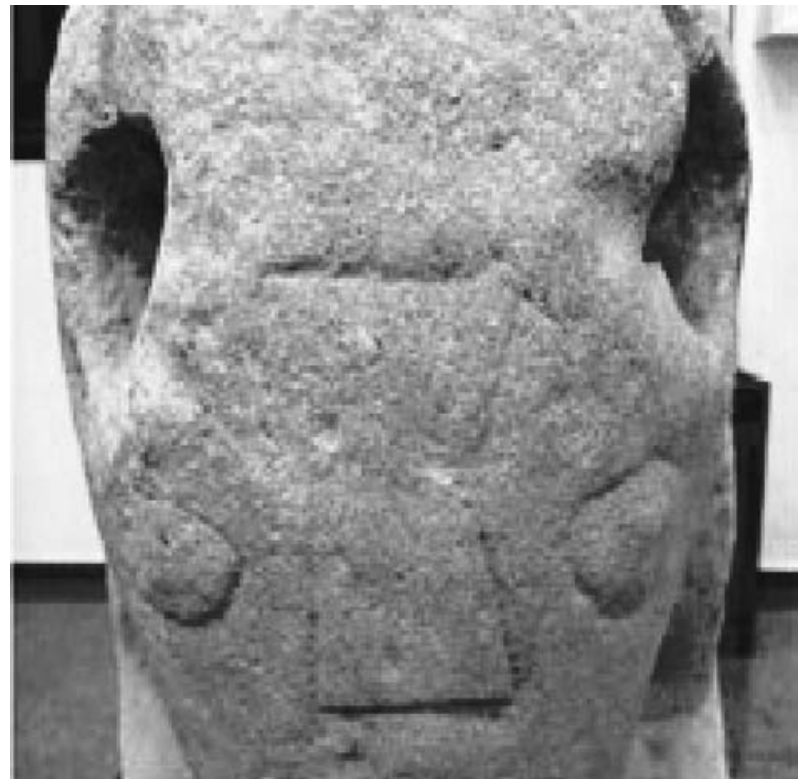

Figura 19: Detalle del taurodermo rebajado en la frente del toro de Monforte del Cid (Alicante) (Chapa et alii, 2009, 734).

\begin{abstract}
"Puede pensarse que esta forma de suplicación, este llamado mudo de ayuda, traspone simbólicamente a un vivo en grandes apuros un tratamiento normalmente reservado a ciertos difuntos. La injusticia sufrida, la impotencia públicamente reconocida, suspenden su vida: se instala sobre la piel mortuoria y se rehúsa a usar las manos" (Dumézil, 1989a, 261).
\end{abstract}

La conexión entre el plano de los vivos y el del Más Allá es aquí posible, del mismo modo que se ha llamado la atención sobre este hecho en la simbología de la piel de bóvido en la resurrección de la divinidad sobre los altares de Caura o de El Carambolo, o en su aparición como decoración del suelo del monumento turriforme de Pozo Moro, por poner sólo dos ejemplos de entre tantos otros. Si no, no se explicaría otro ejemplo a propósito de una tradición realizada en la llanura circasiana y datada al menos desde el siglo III a. C., según la cual el cadáver de un hombre era envuelto en una piel de buey sin curtir como sudario y suspendido de un árbol, lejos de los vivos (Dumézil, 1989a, 259). ¿Qué cabida tiene aquí un pacto? La misma M. C. Marín comenta que la interpretación sobre esta práctica no tiene acuerdo entre los investigadores (Marín, 2006, 48). Sin embargo, desde nuestra perspectiva, es la piel la que protege de los males externos que acechan al cadáver colgando del árbol y sirviendo de nexo de unión entre el plano de los vivos y el del Más Allá (¿acaso también con un carácter de resurrección como en el caso de la divinidad sobre el altar?). En este sentido podría interpretarse también la variante oseta de una tradición narta sobre el héroe Soslan, según la cual al no poder tomar la fortaleza enemiga se hizo cubrir por una piel de buey y fingir estar muerto para ser inspeccionado por el enemigo y entablar lucha cuerpo a cuerpo con él (Dumézil, 1989a, 252-254). La

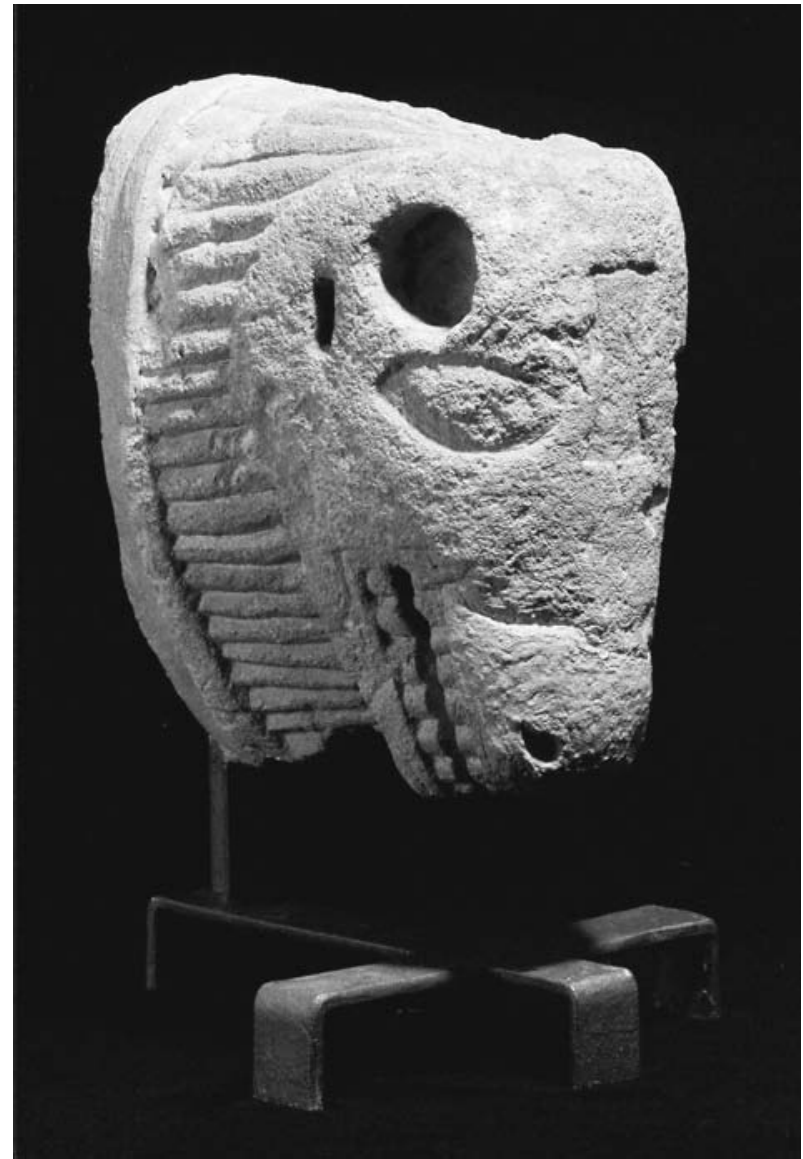

Figura 20: Cabeza de toro hallada en Villajoyosa (Alicante).

vinculación entre la tradición escita y las poblaciones nómadas circundantes, así como el resto de usos y tradiciones en torno a la piel, tanto en el área del norte de Siria como en Asiria, es estrecha. Incluso quizás podamos decir que esta costumbre en la antigua zona de influencia escita continuó existiendo más allá de época romana, como se recoge en el testimonio acerca de Babak, jefe de una secta musulmana fundada por los iranios de Azerbaiján:

"Hizo traer una vaca, dio orden de matarla, de desollarla y de extender la piel por tierra. Puso sobre la piel una copa llena de vino, partió un pan y dispuso los trozos alrededor de la copa. Entonces los fue llamando uno a uno, ordenó a cada uno que hollara con el pie la piel, tomara un pedazo de pan y lo comiera diciendo: "creo en ti, espíritu de Babak, como creo en el espíritu de Javidán", y que entonces fuera a besar la mano a Babak en señal de sumisión. Y todos lo hicieron así" (Dumézil, 1989b, 150-151).

Tampoco hay que dejar de lado, volviendo atrás en el tiempo, que el mito de Jasón, fechable en el siglo $\mathrm{V}$ a. C., transcurre en la Cólquide georgiana, justo en fechas coetáneas al ejemplar de Vani con el que empezábamos nuestro excurso sobre la piel en el mundo escita y que continúa en momentos posteriores de época medieval, por lo que insistimos en que no hay 
que perder de vista la importancia de la piel con un carácter puramente religioso, además del evidente papel comercial que desempeñó.

De estar en lo cierto, la imagen aparecida en los palacios asirios, así como en la tradición escita, no sólo sería la plasmación de un tipo de altar, sino la abstracción de la propia divinidad a la que por aparecer sobre la testuz de animales de clara potencia física con carácter apotropaico podría atribuírsele estas cualidades.

En conclusión, el origen oriental de los altares taurodérmicos de la Península Ibérica ofrece desde nuestro punto de vista poco margen a la duda en el estado actual de la investigación protohistórica. Y si aplicamos una metodología estricta para interpretar como altares las representaciones aparecidas en los cilindrossellos chipriotas y ugaríticos, la misma metodología puede utilizarse para considerar como tales a los símbolos aparecidos en la plástica y en la toréutica asiria y escita, toda vez que ambos símbolos son el mismo. Hasta ahora, la única interpretación con la que nos hemos topado para los taurodermos asirios es la aportada por P. Albenda al decir que puede ser la abstracción de las cuatro partes del mundo, aunque para ello la autora no aporte datos que respalden su hipótesis. Si nuestra idea es acertada en su totalidad o no, futuras investigaciones irán esclareciendo el camino. A falta de interpretaciones más sólidamente construidas, nosotros hemos intentado apuntalar más si cabe la ofrecida por autores como J. Maier y J. L. Escacena.

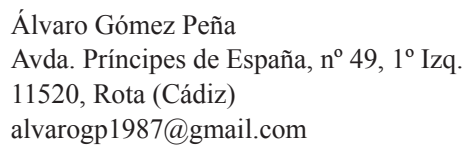

\section{BIBLIOGRAFÍA}

ALBENDA, P., 2005: Ornamental Wall Painting in the Art of the Assyrian Empire, Cuneiform Monographs 28, Boston.

ALMAGRO-GORBEA, M., 1983: "Pozo Moro. El monumento orientalizante, su contexto socio-cultural y sus paralelos en la arquitectura funeraria ibérica», Madrider Mitteilungen, 24, 177-293.

ALMAGRO-GORBEA, M., 2009: «La diosa de Galera, fuente de aceite perfumado», Archivo Español de Arqueología, 82, 7-30.

ALMAGRO-GORBEA, M., 2010: El oro de los argonautas. Tesoros del Museo Nacional de Georgia, Madrid.

AMORES, F. y ESCACENA, J. L., 2003: «De toros y de tesoros: simbología y función de las joyas de El Carambolo», en A. GARCÍA-BAQUERO y P. ROMERO (eds.), Fiestas de toros y sociedad, 41-68, Sevilla.

BASS, G. F., 1961: «The Cape Gelidonya Wreck: Preliminary Report», American Journal of Archaeology, 65, 3, 267-276.

BASS, G. F., 1986: «A Bronze Age Shipwreck at Ulu Burun (Kas): 1984 Campaign», American Journal of Archaeology, 90, 3, 269-296.
BIKAI, P. M., 1987: The Phoenician pottery of Cyprus, A. G. Leventis Foundation, Nicosia.

BLÁNQUEZ, J. J., 1992: "Las Necrópolis ibéricas en el Sureste de la Meseta”, en J. J. BLÁNQUEZ y V. ANTONA (coords.), Congreso de Arqueología Ibérica: las necrópolis, Universidad Autónoma de Madrid, 235-278, Madrid.

BORDREUIL, P. y GUBEL, E., 1990: «Bulletin d'antiquités archéologiques du Levant inédites ou méconnues VI», Syria, 67, 483-520.

CATLING, H. W., 1971: «A Cypriot bronze statuette in the Bomford collection», en C. F. A. SCHAEFFER (dir.), Alasia I, Tome IV, 15-32, Paris.

CELESTINO, S., 1994: «Los altares en forma de «lingote chipriota» de los santuarios de Cancho Roano», Revista de Estudios Ibéricos, 1. La escultura ibérica, 291-310.

CELESTINO, S., 2008: "Los altares en forma de piel de toro de la Península Ibérica”, en J. J. JUSTEL, J. P. VITA y J. Á. ZAMORA (eds.), Las culturas del Próximo Oriente Antiguo y su expansión mediterránea, Instituto de Estudios Islámicos y del Oriente Próximo, 321-348, Zaragoza.

CHAPA, T., BELÉN, M., MARTÍNEZ, M. I., RODERO, A., CEPRIÁN, B. y PEREIRA, J., 2009: «Sculptors' signatures on Iberian stone statues from Ipolca-Obulco (Porcuna, Jaén, Spain)", Antiquity, 83, 321, 723-737.

DUMÉZIL, G., 1989a: Escitas y Osetas. Mitología y sociedad, Fondo de Cultura Económica, México, D. F.

DUMÉZIL, G., 1989b: La cortesana y los señores de colores, Fondo de Cultura Económica, México D. F.

ESCACENA, J. L., 2006: “Allas el estrellero, o Darwin en las sacristías", en J. L. ESCACENA y E. FERRER (eds.), Entre dios y los hombres: el sacerdocio en la Antigüedad, Spal Monografías VII, 103-156, Sevilla.

ESCACENA, J. L., 2007: «El dios que resucita: claves de un mito en su primer viaje a Occidente», en J. J. JUSTEL, J. P. VITA y J. A. ZAMORA (eds.), Las culturas del Próximo Oriente Antiguo y su expansión mediterránea, Instituto de Estudios Islámicos y del Oriente Próximo, 615-651, Zaragoza.

ESCACENA, J. L., 2009: «La Égersis de Melqart. Hipótesis sobre una teología solar cananea», Complutum, 20, 2, 95-120.

ESCACENA, J. L., 2011: "Variación identitaria entre los orientales de Tartessos. Reflexiones desde el antiesencialismo darwinista", en M. ÁLVAREZ (ed.), Fenicios en Tartesos: nuevas perspectivas, BAR International Series 2245, 161-192, Oxford.

ESCACENA, J. L. y COTO, M., 2010: «Altares para la eternidad», Spal, 19, 149-185.

ESCACENA, J. L. e IZQUIERDO, R., 2000: «Altares para Baal», Arys, 3, 11-40.

FERNÁNDEZ, F. y BUERO, M. S., 2010: “El problema del origen y cronología del Bronce Final-Orientalizante en Andalucía occidental, a través del fondo de cabaña de la Universidad Laboral de Sevilla", Temas de Estética y Arte, XXIV, 69-110.

GARCÍA CANO, J. M., 1992: "Las Necrópolis ibéricas en Murcia”, en J. J. BLÁNQUEZ y V. ANTONA (coords.), 
Congreso de Arqueología Ibérica: las necrópolis, Universidad Autónoma de Madrid, 313-348, Madrid.

GARRIDO, J. P. y ORTA, E. M., 1978: Excavaciones en la necrópolis de La Joya (Huelva) II (3. ${ }^{a}, 4 .^{a}$ y $5 .^{a}$ campañas), Excavaciones Arqueológicas en España 96, Ministerio de Educación y Ciencia, Madrid.

GÓMEZ PEÑA, A., e. p.: "Historiografía y metodología taurodérmica protohistórica", Anales de Arqueología Cordobesa, 23.

GÓMEZ PEÑA, A., 2010: “Así en Oriente como en Occidente: el origen oriental de los altares taurodérmicos de la Península Ibérica", Spal, 19, 129-148.

GÓMEZ TOSCANO, F., 2009: "Huelva en el año 1000 a.C., un puerto cosmopolita entre el Atlántico y el Mediterráneo", Gerión, 27, 1, 33-65.

KENNA, V. E. G., 1967: «The seal use of Cyprus in the Bronze Age, II», Bulletin de correspondance hellénique, 91, 2, 552-577.

KUKAHN, E. y BLANCO, A., 1959: «El tesoro del Carambolo», Archivo Español de Arqueología, XXXII, 38-49.

LAYARD, A. H., 1849: Nineveh and Its Remains, II, London.

LAGARCE, J. y LAGARCE, E., 1997: «Les lingots «en peau de boeuf», objets de comerce et symboles idéologiques dans le monde méditerranéen», REPPAL, X, 73-97.

LEBEDYNSKY, I., 2006: Les Saces. Les <<Scythes>> d'Asie, VIII ${ }^{e}$ siècle av. J.-C.-IV siècle apr. J.-C., Editions Errance, Paris.

LÓPEZ PARDO, F., 2006: La torre de las almas: un recorrido por los mitos y creencias del mundo fenicio $y$ orientalizante a través del monumento de Pozo Moro, Universidad Complutense de Madrid, Madrid.

LOUD, G. y ALTMAN, C. B., 1938: Khorsabad. Part II. The citadel and the town, Chicago.

MAIER, J., 2003: "El lingote en rama chipriota o de piel de toro: símbolo divino de la antigua Iberia”, en A.
GARCÍA-BAQUERO y P. ROMERO (eds.), Fiestas de toros y sociedad, 85-106, Sevilla.

MALUQUER DE MOTES, J., 1984 [1970]: Tartessos. La ciudad sin Historia, Ediciones Destino, Barcelona.

MARÍN, M. C., 2006: «De dioses, pieles y lingotes», Habis, $37,35-54$.

MURILLO, J. F., MORENA, J. A. y RUIZ, D., 2005: "Nuevas estelas de guerrero procedentes de las provincias de Córdoba y de Ciudad Real", Romula, 4, 7-46.

NÁCAR, E. y COLUNGA, A., 2008: Sagrada Biblia, Biblioteca de Autores Cristianos, Madrid.

OLKHOVSKIY, V. S., 2000: «Ancient Sanctuaries of the Aral and Caspian Regions: A Reconstruction of their History», en J. DAVIS-KIMBALL, E. M. MURPHY, L. KORYAKOVA y L. YABLONKSY (eds.), Kurgans, Ritual Sites, and Settlements Eurasian Bronze and Iron Age, BAR International Series 890, 33-42, Oxford.

PULAK, C., 1988: «The Bronze Age Shipwreck at Ulu Burun, Turkey: 1985 Campaign», American Journal of Archaeology, 92, 1, 1-37.

RUIZ, A., RÍSQUEZ, C. y HORNOS, F., 1992: "Las necrópolis ibéricas en la Alta Andalucía", en J. J. BLÁNQUEZ y V. ANTONA (coords.), Congreso de Arqueología Ibérica: las necrópolis, Universidad Autónoma de Madrid, 397-430, Madrid.

SCHAEFFER, C. F.-A., 1971: «Les peuples de la mer et leurs santuaires a Enkomi-Alasia aux XIIe-XIe s. av. n. è.», en C. F. A. SCHAEFFER (dir.), Alasia I, Tome IV, 505-573, Paris.

VAN DER TOORN, K., BECKING, B. y VAN DER HORST, P. W., 1999: Dictionary of Deities and Demons in the Bible, Koninklijke Brill NV, Leiden.

ZARAGOZA, J. (trad.), 1990: Luciano. Obras III, Gredos, Madrid. 